\title{
THE MASLOWIAN PORTFOLIO THEORY \\ VERSUS THE PYRAMID PORTFOLIO
}

Sebastian Majewski, Assoc. Prof.

Szczecin University

Mickiewicza 64, 71-101 Szczecin, Poland

e-mail: Sebastian.Majewski@wneiz.pl

Received 29 January 2014, Accepted 5 June 2014

\begin{abstract}
This article refers to De Brouwer's modification of portfolio selection from 2009. He modified the existing portfolio's theories so that they could take into account the Maslov's hierarchy of needs. This proposal could be also an alternative concept to the behavioural portfolio theory. Another theoretical concept which includes not only the hierarchy of needs but the pyramid portfolio is presented in this paper as well. The base point in this case is Markowitz's model and the safety-first criterion by Roy. Such a construction should be a starting point for building an application in this field.
\end{abstract}

Keywords: behavioural portfolio theory, Maslowian portfolio.

JEL classification: G11, G02. 


\section{Introduction}

Modern portfolio analysis no longer deals with seeking just the optimal portfolio content from the point of view of the adopted objective function. It focuses on the processes that take place in the course of investment decision-making. Despite the classical objective function, which determines the search for solutions that guarantee maximum profits while complying additional assumptions, there are other objective functions involving such aspects of economy that have not been brought up before, e.g. purposeful actions that do not require factual backing from the realm of economics, such as social responsibility.

The starting point for the deliberation on the legibility of the approach to the portfolio analysis from the point of view of Maslow's theory of needs was the article by De Brouwer ${ }^{1}$ where he gives the characteristics of the behavioural approach to the portfolio which is squeezed into the framework of the hierarchy of needs. It is an interesting view on the rules of portfolio creation and it definitely conforms to the canon of the behavioural finance. The article addressing this issue is also an attempt to answer the question to what extent the theoretical structure can come near the real-life structure in the course of building a portfolio. As a matter of fact it is not the portfolio structure that is important, but the mechanisms of its creation. We know that it is practically impossible to build a universal model, especially when decision-makers perceive the real world differently.

The purpose of this article is to present such a method of building a portfolio that, with the assumption of the behavioural character of investment decisions made by an average stock trader, makes the decision-making process as objective as possible. Since the article outlines a theoretical basis for such a model, you will not find here empirical examples. Herein the author lays out the Maslowian portfolio theory as well as the pyramid portfolio. He also analyses the option to use the pyramid portfolio as a tool to satisfy the hierarchy of needs.

\section{Behavioural Portfolio}

The Behavioural Portfolio Theory (BPT) was published by Shefrin and Statman². The theory is based on the assumption that people who make investment decisions on the market do not act rationally. It is derived from the behavioural finance which tries to explain market events from the angle of the investors' behaviour on the market. Interest in new theories resulted from the researchers' experience which regularly confirmed that the capital market is hardly predictable and its forecasts are often far from reality. The aforementioned situations have been called financial phenomena and they can be explained by means of models where investors are not fully rational ${ }^{3}$. 
Psychologists say that irrationality is the consequence of the investors' trust in their success as well as it is a derivative of their propensities (e.g. to risk). These two factors determine the fact that their portfolio content does not match the portfolio regarded as optimal in terms of traditional finance.

In papers discussing behavioural finance the authors often describe a certain effect of individual investors' behaviour referred to as mental accounting. It is a substantive basis for the implementation of multi-criteria procedures in the process of portfolio building. In the construction of the behavioural portfolio two terms are combined: mental accounting and the framing effect. The former was first published by Thaler ${ }^{4}$ and it means that every investor has their own internal mental accounting system which frames the ongoing decision-making processes focusing on goals. Consequently, the investments are independent virtual accounts. Thus, in an investor's mind there are goals which make his or her decisions look irrational from the outside. This system is at variance with the popular economic understanding of rationality and is founded in the spheres of emotions. One of such spheres is described in the article by Shefrin and Statman 5 . They found out that closing the position at loss evokes strong negative feelings in an investor, which results in their reluctance to sell securities that are bringing loss. Investors tend to sell securities that bring profit so that they can avoid closing the investment position at loss, against rational analysis. Another sign of emotionality in investment behaviour was pointed out by Odean ${ }^{6}$ who found out that forecasting was performed also on the basis of mental accounting - traders typically forecasted selling of those securities whose prices had recently increased. When deciding on the buy of specific assets for their portfolio people determine in advance their investment utility, ignoring such an important factor as the correlation among the rates of return of the portfolio components. Therefore, a need arises to construct instruments with more than one objective function.

The framing effect refers to the observation that an investor's feelings after their loss can be alleviated only by generating a profit 2 times larger than the loss (curve asymmetry in relation to the point $\mathrm{C})^{7}$. Human needs create the necessity to take several tasks into simultaneous consideration. As a result, we cannot exclude a complex situation when individual risk groups can have globally contradictory goals.

\section{Maslow's Portfolio}

Maslow recognised five levels of needs. He called the first four deficiency needs associated with physiological needs. When these levels are satisfied, an individual will not feel anything, 
but when they are not satisfied, he or she will experience emotional instability. The highest level is called the growth needs, and is associated with psychological sphere. Deficiency needs must be satisfied first. As soon as they are met, an individual focuses on their psychological needs, i.e. self actualisation. The hierarchy of needs comprises the following needs that must be satisfied:

- physiological needs (drinking, eating),

- safety needs,

- social needs (friendship, love),

- esteem needs,

- need for self-actualisation.

De Brouwer points out that it is not possible to convey the so defined human needs into the area of investment. In this way the Maslowian Portfolio Theory (MaPT) was conceived. First, an investor looks for opportunities to secure their financial safety and when that need has been satisfied, and when speculation on the stock exchange is possible, the next needs of higher degree emerge. The author offers the following solutions for building an optimal portfolio with regard to the hierarchy of needs:

- choosing the lowest risk and the highest liquidity (cash only),

- roy's safety-first criterion and the higher moment portfolio,

- SP/A (security-potential/aspiration in the SP/A Theory ${ }^{8}$ ) and the higher moment portfolio,

- SP/A, perhaps MV (mean-variance) or the higher moment portfolio,

- MV or gambling.

De Brouwer motivates his choice in the following way: if the physiological needs are at the bottom of the pyramid of needs, the investor should seek such investments which offer them high liquidity at a very low risk. According to this rule, the best assets are cash and money market funds. Due to limited resources and human pursuit of extra satisfaction, investing does not end on the first level. Depending on an individual's propensity to risk, their financial investments reach increasingly higher levels of needs.

The second level in the hierarchy is the need for safety where the only criterion in the decision-making process is the risk that the decision is carrying. In this case the portfolio is constructed in such a manner that the financial means can be gained for as long as possible. The financial equivalent of the above situation are pension plans and schemes as well as insurance policies with the option to invest a part of funds or of structured products.

When the needs on the first two levels have been satisfied and when the investor still has available funds, the third group of social needs appears, such as investment activities which 
fall within the notion of mental accounting being the foundation of the Behavioural Portfolio Theory.

Contrary to the BPT, the Maslowian Portfolio Theory (MaPT) is a predictive theory, which means that it can be used to support investment decisions and to answer the question: How should the investment portfolio look like?

\section{Pyramid Portfolio}

The Pyramid Portfolio is a combination of the BPT, the Risk Pyramid ${ }^{9}$ and the portfolio building methodology by Markowitz. This idea is based on the concept of multi-criteria decisionmaking, which is often quoted in economic publications ${ }^{10}$.

In order to specify the objective function in such a model, several assumptions have to be made. First of all, we can assume that the investor is trying to maximise the rate of return from their portfolio, either acknowledging the independence of the rates of return of individual securities in risk groups (there actually are independent sub-portfolios) in their portfolio or regarding this dependency as irrelevant. Then the rate of return from this portfolio is written:

$$
\begin{aligned}
& R_{p}=\sum_{j=1}^{k} w_{j} \cdot R_{s j}, \\
& R_{s j}=\sum_{i=1}^{n} x_{i j} \cdot R_{i j}
\end{aligned}
$$

where:

$R_{p}$ - the rate of return from the portfolio,

$w_{j}$ - the share of the risk group in the portfolio,

$R_{s j}$ - the rate of return from the risk group sub-portfolio,

$x_{i j}-$ the share of the $i$-th company in the sub-portfolio,

$i=1,2, \ldots, n$,

$j=1,2, \ldots, k$,

$n-$ the number of securities in the risk group,

$k$ - the number of risk groups (initially 6 - groups from A to F).

Then the correlation among securities for investor is irrelevant in the sense of not taking into account its occurrence in the process of building investment portfolio. In this sense this irrelevance is only in the mental sphere of an individual investor's decision process. 
The objective function for such a model will include the maximisation of the sub-portfolio rates of return, while the total portfolio outcome will be their resultant:

$$
R_{s j}=\sum_{i=1}^{n} x_{i j} \cdot R_{i j} \rightarrow \max
$$

Now we should specify the model restrictions. The first restriction is short-selling. This is the moment where we must make the second assumption that not all the companies can be subject to short sale. Short-selling is conditioned by the market liquidity in regard of a given security. In order to make the reasoning more transparent, the author proposes the following marking of the risk groups, according to the risk pyramid:

A - bonds or other State Treasury securities,

$\mathrm{B}$ - shares of big companies,

$\mathrm{C}$ - shares of medium companies,

D - shares of small companies,

E - flotation shares,

$\mathrm{F}$ - foreign shares.

Polish capital market allows short-selling only in case of securities from the group B. Therefore, when introducing the restriction, it is written:

$$
\begin{aligned}
& x_{i j} \geq 0 \text { for securities from the groups } \mathrm{A} \text { and } \mathrm{C}-\mathrm{F} \\
& x_{i j} \in \mathrm{R} \text { for securities from the group } \mathrm{B} \\
& \sum_{i=1}^{n} x_{i j}=1
\end{aligned}
$$

Another condition restricting the aforementioned objective function is the size of the acceptable risk. Markowitz's theory states that when estimating the risk we should take into account interactions among the rates of return of individual securities in the portfolio. Therefore it is necessary to correct the sum of multiplied variances of the rates of return from the assets and the square of shares in the portfolio by the covariances occurring among them.

However, when we refer to mental accounting, we should give up measuring of the covariances as irrelevant. On the other hand, this element is so important for the correct estimation of risk that it should not be eliminated. So, we should determine a certain acceptable level of risk which will depend on the investment objective. Hence, the fourth restriction refers to the risk level:

$$
S_{p j}=\sqrt{X^{T} \cdot D \cdot X}=\alpha_{j}
$$


where:

$X$ - the vector of the securities share in the sub-portfolio,

$D$ - the matrix of variances and covariances among the portfolio components,

$\alpha_{j}$ - the level of acceptable risk in the group,

thus:

$S_{p}=\sqrt{W^{T} \cdot D \cdot W}$,

$W$ - the vector of the risk group shares in the portfolio,

$D$ - the matrix of variances and covariances among the risk groups in the portfolio.

In the second case we should expect another situation (admitted by Markowitz) when the investor seeks minimum portfolio risk, thus trying to maintain 'right proportions' among the risk groups (sub-portfolios). Therefore, the objective function will be the minimisation of the expression:

$$
S_{p j}=\sqrt{X^{T} \cdot D \cdot X} \rightarrow \min
$$

Under the restricting conditions (1), (2) and (3) written above.

The third analysed case is probably the most common due to the investor's propensities, the complexity of investment objectives and to varying time horizon of the investments. Therefore, the process of portfolio building based on the investment objective and different for each of the risk groups should admit the situation when a different objective function is attributed to each risk group. This leads to a general formula of the model where the basic portfolio parameters are a composition of different objective functions written as:

$$
R_{s j}=\sum_{i=1}^{n} x_{i j} \cdot R_{i j} \rightarrow \max \quad \text { and (particularly next) } \quad S_{p j}=\sqrt{X^{T} \cdot D \cdot X} \rightarrow \min .
$$

Under the restrictions (1), (2), (3) and (4).

In this case the most important parameter in the whole portfolio will be the rate of return $R_{p}$, while the risk parameter $\left(\mathrm{S}_{\mathrm{p}}\right)$ will be of secondary meaning due to its optimisation within the risk group rather than in the portfolio as a whole. Optimal portfolios, i.e. the ones that can be found at the efficient frontier, will be rare in this situation. 


\section{Pyramid Portfolio in the Maslowian Theory Approach}

As it has been mentioned before, the pyramid portfolio is based, inter alia, on the risk pyramid. Hence, we have two dimensions of the pyramid: the share in the portfolio and the size of risk depending on the capital involved. For the portfolio to meet the requirement of the hierarchy of needs, it should be supplied with the third dimension (parameter), i.e. the liquidity for the first level needs. So, the corrected objective function should be composed of two autonomous functions:

$$
S_{p j}=\sqrt{X^{T} \cdot D \cdot X} \rightarrow \min \quad \text { and } \quad L_{p j}=\frac{V_{p j}}{V_{g}} \rightarrow \max
$$

where:

$L_{p j}$ - the liquidity of the $j$-th portfolio counted as the average weighted with the shares of securities in the portfolio,

$V_{p j}$ - turnover volume of the $j$-th portfolio counted as the sum of turnovers of all the assets included in the portfolio,

$V_{g}-$ global volume of turnovers on the market from which the securities come from.

Here the restrictions (1), (2) and (3) should be introduced, as in the case of the risk minimising objective function.

Of course, to reduce the risk of fluctuation to zero all we can withdraw from the portfolio is cash and nothing but cash. Then the investor will be exposed merely to the risk of storing cash. It should be noted, however, that according to the prospect theory the shape of a curve depicting the investors' motivation propensity relies on several factors. In regard to this discussion two of them are crucial: sensitivity to changes in the portfolio ${ }^{11}$ and the reference point $c$. In the former case we should concentrate more on the investors' sensitivity to likely losses. Then the form of the objective function could be constructed including the synthetic variable - the frame coefficient $(\mathrm{FC})^{12}$. The idea of frame coefficient comes directly from The Prospect Theory of Kahneman and Tversky (this approach is explained under the Figure 1). The objective function could be written:

$$
F C_{p j}=\frac{R_{p j}}{S_{p j}} \rightarrow \kappa \quad \text { and } \quad L_{p j}=\frac{V_{p j}}{V_{g}} \rightarrow \max
$$

where:

$F C_{p j}$ - the frame coefficient $F C$ for the $j$-th portfolio,

$\kappa-$ the constant which defines the relation to risk (standard by Kahneman and Tversky is 2.0). 


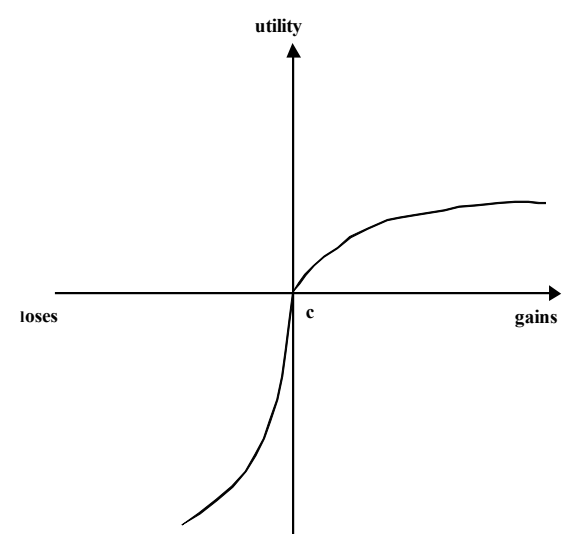

Fig. 1. Investors' motivation propensity depending on the reference point in the prospect theory Source: Kahneman, Tversky (1979).

If we assume that, according to Kahneman and Tversky, on average this value is 2.0, then the fact results from the mathematical dependence (the way $F C$ is calculated) that the value of the coefficient should rise along the increasing aversion to risk. Therefore, assuming a low value of the reference point $c$ for the curve, we can generalise that $\kappa$ should approximate the maximum.

In the latter case, with regard to the importance of the reference point it should be emphasised that the determination of the reference point which is appropriate for an individual investor will decide whether physiological needs can be satisfied (according to the Maslowian theory). So, the conclusion is that the available income determines the character of primary needs. It is likely, therefore, that this is why in the case of the well-off investors the first group of needs will be composed of safety needs. In addition, it is hard to believe that the investor with no free cash flow will focus on investment goals. Hence, it seems reasonable to start building the investment portfolio from the safety criterion. Thus, the first of the analysed independent objective functions for the pyramid portfolio would be:

$$
\mathrm{L}(\mathrm{x})=\frac{\overline{R_{p}}-R_{L}}{\mathrm{~S}_{\mathrm{p}}} \rightarrow \max ,
$$

where:

$R_{p}$ - the rate of return from the portfolio,

$R_{L}$ - the rate of return from the portfolio below which the values are not acceptable for the investor. 
In this case the measurement of risk for sub-portfolios created simultaneously would not differ from the classical Markowitz form, i.e. it would take into consideration covariances among the assets. The remaining restrictive conditions would be similar to the general form of the behavioural portfolio.

The third, fourth and fifth need could be included in the considerations as a consequence of the application of the standard form of the pyramid behavioural model.

As a result, from the Maslowian theory perspective the pyramid portfolio would have six differently oriented objective functions thanks to which it would meet the hierarchy of needs. Mental accounting, the effect of which is the need to analyse the investment in isolation from the correlations among the portfolio components while simultaneously prioritising individual objectives in the process of portfolio building, encourages us to treat every suggestion concerning sub-portfolio construction as autonomous instruments of the decision-making process. Such portfolio will never be on the efficient frontier (on the authority of Markowitz's theory), but it will take into account the needs arising from the human nature.

\section{Conclusions}

De Brouwer proposed the concept of the Maslowian portfolio on the basis of the concepts of its construction that had already existed in the portfolio analysis. It seems, however, that although he presented the idea as an alternative to BPT, he ignored the factors underlying the concept of the behavioural portfolio, i.e. the motivation curve and mental accounting.

Proposed in this paper the expanded concept of the pyramid portfolio based on the Maslowian theory seems to address better the problem of constructing a behavioural portfolio and it does not reject De Brouwer's proposals. It can be regarded as a set of instruments to support the decision-making process that can be expanded by new components every time the investor's need arises.

\section{Notes}

${ }^{1}$ De Brouwer (2009), pp. 359-365.

${ }^{2}$ Shefrin, Statman (2000).

${ }^{3}$ Barbies, Thaler (2002).

${ }^{4}$ Thaler (1999), pp. 183-206.

${ }^{5}$ Shefrin, Statman (2000).

${ }^{6}$ Odean (1998), pp. 1887-1934. 


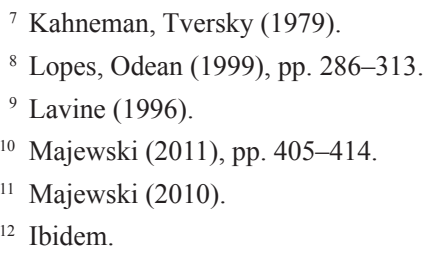

\section{References}

Barberis, N. \& Thaler, R. (2002). A Survey of Behavioral Finance. Handbook of the Economics of Finance.

De Brouwer, P.J.S. (2009). Maslovian portfolio theory, an alternative formulation of the Behavioral Portfolio Theory. Journal of Assets Management, 9 (6).

Kahneman, D. \& Tversky, A. (1979). Prospect Theory: An Analysis of Decision under Risk. Econometrica, 47 (2).

Lavine, A. (1996). Wszystko o funduszach powierniczych. Warszawa: WIG-Press.

Lopes, L.L. \& Oden, G.C. (1999). The Role of Aspiration Level in Risky Choice: A Comparison of Cumulative Prospect Theory and SP/A Theory. Journal of Mathematical Psychology, 43.

Majewski, S. (2010). Methodological Aspects of Behavioural Portfolio with Multitasking, Folia Oeconomica Stetinensia, 9 (17).

Majewski, S. (2011). Wielokryterialność w modelowaniu składu portfeli papierów wartościowych. Finanse - nowe wyzwania teorii i praktyki. Rynek finansowy. Wrocław: Prace Naukowe Uniwersytetu Ekonomicznego we Wrocławiu.

Odean, T. (1998). Volume, Volatility, Price and Profit When All Traders Are Above Average. The Journal of Finance, 53 (6).

Shefrin, H. \& Statman, M. (2000). Behavioral Portfolio Theory. Journal of Financial Quantitative Analysis, 35 (2).

Tarczyński, W. (1997). Rynki kapitałowe. Metody ilościowe. Vol. II. Warszawa: Placet.

Thaler, R.H. (1999). Mental Accounting Matters. Journal of Behavioral Decision Making, 12. 